\title{
Study of United Kingdom product licence applications containing new active substances, 1987-9
}

\author{
Michael D Rawlins, David B Jefferys
}

\begin{abstract}
Objectives-To investigate the fate of product licence applications containing new active substances in relation to their degree of innovation and therapeutic category. To assess the numbers of volunteers and patients exposed to a new active substance when marketing authorisation is first sought.

Design and setting-Observational study of records for each licence application submitted to the United Kingdom licensing authority for marketing authorisation from 1987 to 1989.
\end{abstract}

Subjects-118 product licence applications containing one or more new active substances.

Main outcome measures-Success of application for product licence as assessed by the decision of the Committee on Safety of Medicines to advise the granting of a licence (with or without conditions) or provisionally advise its refusal on the grounds of quality, safety, or efficacy. Assessment of numbers of volunteers and patients exposed to each substance during premarketing studies and clinical trials, and the numbers of treated patients available for an assessment of safety.

Results-118 relevant product licence applications were submitted during the review. Although $60 \%(52 / 86)$ of semi-innovative products fell into one of three therapeutic categories (cardiovascular, central nervous system, or anti-infective agents), only $41 \%(13 / 32)$ of fully innovative products fell into these categories. 47 applications were granted (conditionally or unconditionally) but the success rate for fully innovative products $(56 \%, 18 / 32)$ was greater than that for semi-innovative products $(34 \%, 29 / 86)$. The number of volunteers and patients exposed to a new product at submission varied widely and tended to be greater for successful applications.

Conclusion-The results suggest a broadening of the pharmaceutical industry's research and development programmes and that a more liberal licensing policy exists for fully innovative products than for semi-innovative products. The relatively limited exposure of patients to new active substances at licensing underlines the importance of rigorous postmarketing surveillance.

\section{Introduction}

Authorisation to market a new active substance as a medicine is one of the most important decisions made by a national drug regulatory authority. In the United Kingdom a product licence for a new active substance is currently granted by the licensing authority only after consultation with the Committee on Safety of Medicines, whose advice has been invariably accepted.

The review procedure entails the preparation of assessment reports (pharmaceutical, scientific, and clinical) by the professional staff of the Medicines
Control Agency before a careful examination of the application by the committee's specialï subcommittees (chemistry, pharmacy, and standards; safety, efficacy, and adverse reactions; and, where relevant, biological substances and biotechnology). The assessment reports and the subcommittees' views are then considered by the main committee.

We report the initial fate of product licence applications whose constituents included one or more new active substances and which were considered by the committee in 1987-9. In the United Kingdom, however, there are two formal appeal mechanisms - one to the committee itself and then to the Medicines Commission-which may be invoked by manufacturers after initial (provisional) objections have been raised.

\section{Methods}

In 1987-9 the Committee on Safety of Medicines considered 118 applications containing one or more new active substances. Four new active substances were the subject of two separate applications by different manufacturers, and two applications contained two new active substances. For each application we recorded its therapeutic category (using the British National Formulary classification); the date the application was received by the Medicines Control Agency; the date of its consideration by the committee; and whether the committee advised the granting of a product licence (with or without conditions). In those instances where the committee advised the provisional rejection of a licence application the reasons were also recorded. For each application we also recorded the numbers of healthy volunteers exposed to a new active substance during premarketing studies, the numbers of patients treated with the product during clinical trials, and the total numbers of treated patients avail- $N$ able for an assessment of safety. The degree of $\rightarrow$ innovation of each new active substance was assessed using the criteria previously described': under this $N$ classification all the products under review were either స్心 fully innovatory or semi-innovatory.

\section{Results}

The 118 new active substances submitted fell into 14 British National Formulary therapeutic categories (table I) but there was also a fifteenth group, compris- $\mathbb{\cap}$ ing radiological contrast media and radioisotopic diagnostic agents (radiodiagnostics). Overall, 65 of the 118 applications fell into one of three therapeutic categories (cardiovascular, central nervous system, or anti-infective agents). Thirty two of the applications were for fully innovative products (table I), with only $13(41 \%)$ of these in the three dominant therapeutic categories compared with $52(60 \%)$ of the semi-innovative products.

For 47 applications the committee advised (table II) 
the granting of a product licence either conditionally (46) or unconditionally (1). The 25 minor conditions required only modification to the product's datasheet, but the major conditions required either restrictions to the licensed indications (15) or the satisfactory completion of routine mutagenicity studies (4), or both (2). In all instances manufacturers were able to meet the conditions. Of the unsuccessful applications (table II), most were declined on grounds of both safety and efficacy. The proportions of successful applications were similar between therapeutic categories but the overall success rate of fully innovative new active substances $(18,56 \%)$ was greater than that of semiinnovative products $(29,34 \%)$.

The median assessment times for all applications ( 32 weeks; interquartile range $27-38$ weeks) tended to be shorter for successful applications (31 weeks; 26-37 weeks) than for unsuccessful ones (34 weeks; 28-39 weeks). There was a trend for median overall assessment times to be shorter in 1989 ( 29 weeks) than in 1987 (37 weeks) despite the greater number of products assessed in 1989 (43) than in 1987 (31).

The number of volunteers and patients receiving a new active substance in support of a marketing application during the review period varied widely between products (table III). Overall, there was a tendency for greater numbers of volunteers and patients to be included in successful applications than in unsuccessful ones.

\section{Discussion}

Drug regulatory authorities rarely publish detailed accounts of their work. Griffin and Diggle described drug licensing of new active substances in the United Kingdom, between 1972 and 1981, but their analysis was predominantly operational. ${ }^{2}$

Our study reports the initial fate of licensing applications for new active substances considered by the committee in 1987-9. The distribution of applications between therapeutic categories, with cardiovascular,

TABLE I-Distribution of new active substances according to therapeutic group

\begin{tabular}{lcc}
\hline & \multicolumn{2}{c}{ Applications } \\
\cline { 2 - 3 } & $\begin{array}{c}\text { Total } \\
\text { (successful) }\end{array}$ & $\begin{array}{c}\text { Fully } \\
\text { innovative } \\
\text { (successful) }\end{array}$ \\
Therapeutic category & $8(3)$ & $3(1)$ \\
Gastrointestinal system & $33(13)$ & $3(2)$ \\
Cardiovascular system & $5(1)$ & \\
Respiratory system & $16(4)$ & $4(3)$ \\
Central nervous system & $17(8)$ & $6(3)$ \\
Infections & $9(3)$ & $5(2)$ \\
Endocrine system & 2 & \\
Obstetrics, gynaecology, and urinary tract & & \\
disorders & $5(2)$ & 2 \\
Malignant disease and immunosuppression & $4(2)$ & $2(1)$ \\
Nutrition and blood & 2 & 1 \\
Musculoskeletal and joint diseases & $1(1)$ & $1(1)$ \\
Ear, nose, and oropharynx & $6(4)$ & $2(2)$ \\
Skin & $2(1)$ & $1(1)$ \\
Immunological products and vaccines & $1(1)$ & $2(2)$ \\
Anaesthesia & $7(4)$ & $32(18)$ \\
Radiodiagnostics & $118(47)$ & \\
\hline Total &
\end{tabular}

TABLE II - Fate of 118 licence applications

\begin{tabular}{lcc}
\hline Fate & $\begin{array}{c}\text { Total } \\
\text { applications }\end{array}$ & $\begin{array}{c}\text { Fully } \\
\text { innovative } \\
\text { applications }\end{array}$ \\
\hline Successful: & 47 & 18 \\
Unconditionally & 1 & 1 \\
With minor conditions & 25 & 6 \\
With major conditions & 21 & 11 \\
Unsuccessful on grounds of: & 71 & 14 \\
Safety and efficacy & 55 & 9 \\
Safety & 14 & 5 \\
Efficacy & 2 & \\
\hline
\end{tabular}

TABLE III-Median numbers (range) of volunteers and patients exposed to new active substances during premarketing studies

\begin{tabular}{lccc}
\hline & $\begin{array}{c}\text { Healthy } \\
\text { volunteers }\end{array}$ & $\begin{array}{c}\text { Efficacy } \\
\text { studies }\end{array}$ & $\begin{array}{c}\text { Safety } \\
\text { database }\end{array}$ \\
\hline All applications & $68(0-819)$ & $861(41-4906)$ & $1171(43-15962)$ \\
Successful applications & $92(0-819)$ & $1126(122-4906)$ & $1480(129-9400)$ \\
Unsuccessful applications & $64(0-431)$ & $785(41-4786)$ & $1052(43-15962)$
\end{tabular}

central nervous system, and anti-infective agents predominating, largely reflects the contemporary pharmaceutical market. Although only a quarter of new active substances were fully innovatory, their distribution between therapeutic categories was wider than that of semi-innovatory substances, suggesting a broadening of the pharmaceutical industries' research and development programmes. Moreover, the success rate for fully innovatory new active substances seems to be greater than that for semi-innovatory ones. There are at least two possible reasons for this. Firstly, the premarketing development of fully innovatory substances, often by highly experienced and successful companies, may be performed more skilfully. Alternatively, as fully innovatory substances have (by definition) novel properties and tend to be indicated for conditions less well served by existing drugs the Committee on Safety of Medicines may undertake a more liberal risk-benefit assessment. We suspect that both factors apply. Manufacturers, however, have rights of appeal against initial (provisional) negative decisions of the committee irrespective of a substance's innovatory state. Indeed, of the 71 unsuccessful applications, 24 had (by March 1990) been granted licences on appeal, usually after the submission of additional data.

Perhaps surprisingly 56 applications were rejected on grounds of inadequate evidence of efficacy. In a few instances this was due either to uncertainty about a product's long term efficacy (six applications) or to the failure to show efficacy throughout a dosage interval (three). In most cases, however, the committee and secretariat were unconvinced of the overall efficacy of products for the indications claimed.

Concerns about clinical safety at initial assessment are, perhaps, less surprising. Such issues require riskbenefit decisions that are generally resolved by judgmental analysis. Differences in such risk-benefit assessments between commercial innovators and the Committee on Safety of Medicines are at the heart of drug regulation. It is disappointing, though, that nearly half of the applications provided deficient preclinical safety data on general toxicity testing, mutagenicity screening, and carcinogenicity studies. Although in some instances these entailed differences in data interpretation between the committee and secretariat on the one hand and the companies' experts on the other, most decisions were based on inadequacies in both the design and conduct of studies. As detailed guidelines for the conduct of preclinical studies, agreed throughout the European Community, are generally available ${ }^{3}$ the reasons for these inadequacies are unclear.

The time taken for the assessment of new active substances is critically important to pharmaceutical manufacturers. It may also be of concern to doctors and their patients if administrative delays impede the wide availability of important therapeutic agents. The current assessment times are longer than we would want, but there are several factors that need to be considered. Firstly, each assessment (pharmaceutical, scientific, and clinical) takes about four weeks and needs to be performed consecutively. Secondly, applications are assessed and considered by the committee in strict order of submission; as applications are often spaced unevenly a backlog can easily arise. Thirdly, unsuccessful applications tend to take longer 
to assess than successful ones often because of deficiencies requiring informal or formal contacts with the company to try to resolve them. There is a mechanism for "fast tracking" some assessments to make available new products of major importance in public health. This mechanism was used twice during the review period, with an average assessment time of 10 weeks.

To our knowledge the number of people taking part in premarketing studies has never previously been reported by a drug regulatory authority. Table III clearly shows that the numbers of healthy volunteers used to support product licence applications are sometimes considerable. Such investigations, with safeguards, make substantial contributions to the development of new drugs. Clearly also the numbers of patients exposed to new active substances before marketing vary widely. For agents shown to be effective in an otherwise lethal condition relatively small numbers of subjects may be required to show safety and efficacy. In contrast, much larger numbers of patients will need to be studied to reassure the manufacturer and the committee of the safety of products intended for common conditions, those with a more benign natural history, and those for which alternative treatments are available. Obviously, the number of subjects (volunteers and patients) exposed to most new active substances before marketing can only provide provisional reassurance about safety in a larger and more heterogeneous population. Our data underline the importance of vigilant safety surveillance after marketing.

1 Lunde I, Dukes MNG. Les répercussions du control administratif de médicaments: étude comparée de la situation en Norvège et aux Pays-Bas Industrie Santé 1980;49:37-57.

2 Griffin JP, Diggle GE. A survey of products licensed in the United Kingdom from 1971-1981. Br f Clin Pharmacol 1981;12:453-63.

3 Committee for Proprietary Medicinal Products. Guidelines on the quality, safety and efficacy of medicinal products for human use. In: Rules governin medicinal products in the European Community; vol 3. Brussels: Commission of $\vec{O}$ the European Communities, 1989.

(Accepted 12 November 1990

\section{The NHS Observed}

\section{Junior doctors' years: training, not education}

\section{John Roberts}

Graduate medical education is a brutal enterprise in Britain. Junior doctors seem more like apprentices to a craft than students of a profession: their hours are long, the duration of their training is uncertain, and their futures depend on the whims of consultants. Defenders of the system argue that juniors' training years are a time of "hands on" work that builds dedicated doctors who are skilled and compassionate and practise with a healthy scientific scepticism. But scepticism seems to have spilled over into cynicism: "When I finally get to the top [of the medical pyramid] I can rest, and maybe all this pain will be worth it," said a senior house officer.

In this time of upheaval and change in British medicine all professionals are worried. But none seem as truly miserable as junior doctors. British house staff seemed demoralised, with many anxieties: over the long hours, uncertain futures, dependency on senior staff, changing roles in hospitals that themselves are in the midst of changing roles, and fluctuating government policies.

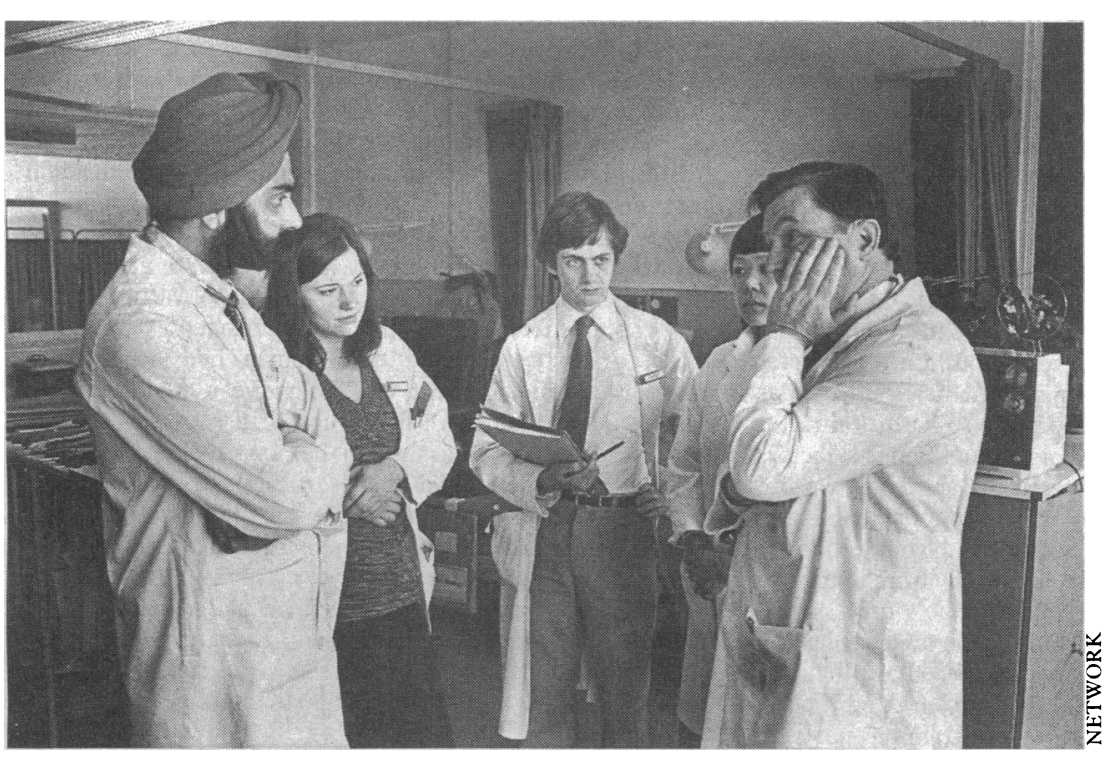

Will their consultant give them a reference?
The very title junior doctor implies something different from the American counterpart, the resident. The resident is one step beyond student status: education is the stated goal. "While you're here your priority is to learn," our chairman told us on our first day as . residents in America. "Patient care comes second as you have the help of attending [senior] physicians at all times." Junior doctor implies apprentice, and service duties seem to preclude all but informal and haphazard education. House officers I interviewed said that formal conferences were scheduled but were mostly attended by consultants: junior staff were too busy with patients.

\section{Fatigue from long nights and long years}

The saga of the long hours of junior doctors has been well described. Over 115 hours of duty a week is not unheard of, and hospital leaders defend this. ${ }^{1}$ The average is 93 hours a week, according to the Department of Health, though this is a crude estimate. Fatigue, juniors argue, leads to disasters such as forgetting to set a ventilator alarm before a heart $\tilde{N}$ transplant operation, resulting in the patient dying of anoxia. ${ }^{2}$ A patient with leukaemia died because a house officer, who had been awake for 30 hours, injected vincristine rather than methotrexate into her central nervous system. ${ }^{3}$ Oddly, to an American, patients seem to be sympathetic about such mistakes. One, whose epidural anaesthesia had worn off during her 27 hour labour, defended the house officer: "When I began my labour he'd already been up 36 hours. I got poor care, but he was exhausted."

In America patients and families are not sympathetic, they're angry. The name Libby Zion is well known to most American house officers because it was her death that angered the public, which demanded that doctors reform themselves. The young woman died in 1984 because exhausted house officers misdiagnosed her systemic infection. The lawsuit brought by her father resulted in nationwide reforms in the conditions and hours of work of doctors in training.

British junior doctors' long hours are gruelling, but this is exaggerated by the uncertainty over how long 